\title{
Reflexões sobre a felicidade como dever do Estado e direito do cidadão
}

\author{
Reflections on happiness as a duty of the State and citizen's right \\ Reflexiones sobre la felicidad como deber del Estado y derecho ciudadano
}

Recebido: 08/02/2021 | Revisado: 12/02/2021 |Aceito: 14/02/2021 | Publicado: 21/02/2021

\author{
Kesia Kiss Nunes \\ ORCID: https://orcid.org/0000-0001-7988-4790 \\ Universidade Federal de Goiás, Brasil \\ Email: kesiasejudh@gmail.com
}

\begin{abstract}
Resumo
O direito à felicidade tem se revestido de especial relevância em diversos países, tais como Japão, Butão e Nigéria, culminando na positivação desse direito em suas cartas magnas. Assim, o presente trabalho busca explorar, por meio de revisão bibliográfica, o conceito de felicidade visando demonstrar que esse direito se traduz em uma das dimensões da dignidade da pessoa humana, que nos permite reclamar por sua positivação na Constituição Federal de 1988, como dever do Estado Brasileiro, todavia, o trabalho debruça também na preocupação entre linha tênue existente entre a legítima positivação da felicidade e nefasta "felicitocracia".
\end{abstract}

Palavras-chave: Direito à felicidade; Positivação da felicidade; "Felicitocracia".

\begin{abstract}
The right to happiness has been of particular relevance in several countries, such as Japan, Bhutan and Nigeria, culminating in the affirmation of this right in their letters. Thus, the present work seeks to explore, through bibliographic review, the concept of happiness, aiming to demonstrate that this right translates into one of the dimensions of the dignity of the human person, which allows us to claim for its positivism in the Federal Constitution of 1988, as duty of the Brazilian State, however, the work also focuses on the concern between a fine line existing between the legitimate positivization of happiness and the nefarious "felicitocracy".
\end{abstract}

Keywords: Right to happiness; Positive happiness; "Felicitocracy".

\section{Resumen}

El derecho a la felicidad ha sido de especial relevancia en varios países, como Japón, Bután y Nigeria, culminando con la afirmación de este derecho en sus cartas. Así, el presente trabajo busca explorar, a través de la revisión bibliográfica, el concepto de felicidad, con el objetivo de demostrar que este derecho se traduce en una de las dimensiones de la dignidad de la persona humana, lo que nos permite reivindicar su positivismo en la Constitución Federal. de 1988, deber del Estado brasileño, sin embargo, el trabajo también se centra en la preocupación entre una delgada línea que existe entre la legítima positivización de la felicidad y la nefasta "felicitocracia".

Palabras clave: Derecho a la felicidad; Felicidad positiva; "Felicitocracia".

\section{Introdução}

O tema acerca da felicidade remonta às discussões filosóficas da antiguidade até os dias atuais. As primeiras notícias estão hospedadas nos escritos de Tales de Mileto, para quem a felicidade cingia-se em ter corpo forte e são, boa sorte e alma formada. Séculos mais tarde, o conceito de felicidade desenvolvido por Aristóteles foi visceralmente associado a prática da atividade virtuosa, afirmando em seu magistério que:

Outra crença que se harmoniza com a nossa concepção é a de que o homem feliz vive bem e age bem; pois definimos praticamente a felicidade como uma espécie de boa vida e boa ação. As características que se costuma buscar na felicidade também parecem pertencer todas à definição que demos dela. Com efeito, alguns identificam a felicidade com a virtude, outros com a sabedoria prática, outros com uma espécie de sabedoria filosófica, outros com estas, ou uma destas, acompanhadas ou não de prazer; e outros ainda também incluem a prosperidade exterior. Ora, algumas destas opiniões têm tido muitos e antigos defensores, enquanto outras foram sustentadas por poucas, mas 
eminentes pessoas. E não é provável que qualquer delas esteja inteiramente equivocada, mas sim que tenham razão pelo menos a algum respeito, ou mesmo a quase todos os respeitos. (Aristóteles, p. 15-16).

Nessa senda, sintetiza (Aristóteles, 2002, p. 17,) que "a felicidade é, pois, a melhor, a mais nobre e a mais aprazível coisa do mundo."

Com efeito, no que tange ao estudo da felicidade, nos impõe ligeiro questionamento: a quem compete esse encargo? Somos credores do direito à felicidade como obrigação Estatal? Uma vez positivada a felicidade na Constituição Federal, não correríamos o risco de instaurar uma "felicitocracia", isto é, ditadura da felicidade? A felicidade decorreria diretamente da dignidade da pessoa humana?

Nesse palco, propomos um estudo teórico bibliográfico colimando explorar o conceito de felicidade, bem como tentando demonstrar (despretensiosamente) que o direito à felicidade se traduz em uma partícula fundamental para a prevalência da dignidade da pessoa humana, reclamando por sua positivação na Constituição Federal de 1988 como dever do Estado Brasileiro.

\section{Metodologia}

Para desenvolver o estudo acerca do direito à felicidade como dever do Estado e direito do cidadão foi eleita a pesquisa teórico-reflexiva, construída com base na Declaração Americana de 1776, Constituição do Butão e relatório mundial da felicidade que possui em seu bojo os parâmetros para se aferir "o grau de felicidade" dos países participantes.

Outrossim, foi utilizada a pesquisa qualitativa, haja vista que ao contrário dos métodos das ciências sociais, a qualitativa abarca como objeto de estudo praticamente todo acontecimento da vida real Yin (2016), sendo a felicidade um deles, para tanto buscamos também suporte na revisão bibliográfica partindo do conceito de felicidade como a prática da virtude (Aristóteles, 2002), perpassando pelo princípio da dignidade da pessoa humano, sob diretrizes teóricas de Immanuel Kant, a fim de fundamentar a felicidade como direito do cidadão a ser positivado pelo Estado.

\section{O que é Felicidade?}

Segundo o Novo Dicionário Aurélio, felicidade é um substantivo feminino, que deriva do latim felicitate, significando "qualidade ou estado de feliz, ventura, contentamento." (p. 767). Em grego, a felicidade é derivada da palavra eudaimonia, cujo prefixo eu significa bom e daimon, demônio. Segundo o filósofo Gregório, essa combinação forma

a palavra eudaimon que, literalmente, significa "bom demônio". Traduzindo-a por "bom deus", "bom espírito", "bom anjo da guarda" e, por conseguinte, "felicidade", pois toda pessoa que tivesse um bom demônio era considerada feliz.", sendo infeliz aquele que tivesse um mau demônio (Gregorio, 2013, online).

No entanto, para Aristóteles, a felicidade é uma virtude, ou seja é um bem supremo encontrado na prática da virtude:

Também nossa concepção se harmoniza com a dos que identificam a felicidade com a virtude em geral ou com alguma virtude particular, pois a felicidade é a atividade conforme à virtude.”.(Aristóteles, 2002, p. 29)

Percebe-se, portanto, por essas mínimas referências a complexidade em torno do conceito de felicidade, notadamente pela tamanha abstratividade que envolve o estudo desse substantivo ao qual nos debruçamos. Embora estejamos distantes de fixar um conceito exato, hodiernamente, o tema tem ganhado peso nas discussões internacionais. 
Prova disso é o fato de que, em 2012, foi elaborado o Relatório Mundial da Felicidade (Correio Braziliense, 2019), cujos critérios utilizados no inquérito para se aferir o grau de felicidade de cada país, leva em conta seis variáveis. São elas: rendimento, confiança, esperança de vida saudável, apoio social, liberdade e generosidade.

Em 2020, ano da pandemia pela Covid -19, as Nações Unidas publicaram o Relatório Mundial da Felicidade de 2020, considerando 153 países, que classificaram dez países mais felizes do mundo nesse ano, na seguinte ordem de colocação: Finlândia $\left(1^{\circ}\right)$, Dinamarca $\left(2^{\circ}\right)$, Suíça $\left(3^{\circ}\right)$, Islândia $\left(4^{\circ}\right)$, Noruega $\left(5^{\circ}\right)$, Holanda $\left(6^{\circ}\right)$, Suécia $\left(7^{\circ}\right)$, Nova Zelândia $\left(8^{\circ}\right)$, Áustria $\left(9^{\circ}\right)$ e Luxemburgo $\left(10^{\circ}\right)$.

Os Estados Unidos da América, que em 2012, ocupavam a $11^{\mathrm{a}}$ posição, embora oscilando ao longo dos anos, regrediu 7 posições, passando em 2020, para a $18^{\mathrm{a}}$ colocação no Relatório de 2020. O Brasil, por sua vez, encontra-se na 32a colocação, sendo o quarto classificado na América Latina, ficando atrás da Costa Rica, México e Chile. A melhor posição ocupada foi no Governo da Presidenta Dilma Rousseff, quando alcançou a $17^{\mathrm{a}}$ colocação no ranking mundial da felicidade, o que confere assertividade à frase da então Presidenta de que nunca fomos tão felizes! De lá para cá, a exemplo dos Estados Unidos, o Brasil sofreu queda vertiginosa de posição, de acordo com a ONU, saindo da $17^{\mathrm{a}}$ posição para $32^{\mathrm{a}}$. Isso demonstra que esses países têm falhado gravemente com o seu povo, colocando-os à margem dos pilares da felicidade.

Assim, entendemos que a felicidade reside no eterno caminhar ou na eterna luta contra as desigualdades sociais. Em outras palavras, a felicidade sempre estará a um passo adiante, na esquina da frente, na curva da vida, nos obrigando a movimentarmo-nos, sempre nos (re)construindo para desmantelar as barreiras que nos impedem de alcançar as condições objetivas para felicidade.

\section{Direito à Felicidade como Dignidade da Pessoa Humana}

Para Immanuel Kant, o homem é um fim em si mesmo e não um meio para a consecução de um fim. Logo "quando uma coisa está acima de todo o preço e, portanto, não permite equivalente, então tem ela dignidade” (Kant, 2000, p. 77). Essa noção de dignidade afasta taxativamente toda e qualquer possibilidade de objetificação ou instrumentalização do ser humano. Eis que a humanidade, então, se reveste de dignidade.

Nesse sentido, arremata Adela Cortina:

A existência de pessoas é, pois, a razão de que haja obrigações morais; porque, como são valiosas em si mesmas, não há equivalente para cada uma delas, assim como não há possibilidade de fixar-lhes um preço. Mas têm dignidade, e quem tem dignidade não é trocável, mas respeitável." (Cortina, 2009, p. 85).

Da dignidade decorrem direitos outros imprescindíveis para a concretização do ser humano como um fim em si mesmo, tais como: o direito à vida, saúde, liberdade, educação, moradia, dentre outros. E por que não incluir, nesta lista, o direito à felicidade?

Com efeito, importa registrar que não é exaustivo o rol de direitos que decorrem da dignidade da pessoa humana, eis que, para o ser humano ser pleno é imprescindível a felicidade. Ter dignidade humana importa em ter saúde, boa alimentação, moradia digna, liberdade, integridade física, moral e intelectual, acesso aos bens e serviços, dentre outros que encampam a concretização da felicidade como decorrência da dignidade.

Não podemos sequer cogitar que pessoas enfermas privadas do acesso à saúde pelo Estado sejam felizes. De igual maneira, àquelas expostas à extrema pobreza, privadas até mesmo de água para matar a sede. É inadmissível que pessoas levando uma vida tão precária, procurando restos de alimentos no lixo e água em esgotos possam ser felizes. 
Contrariando nosso entendimento, a Jornalista e Escritora Chinesa, Xinran, em seu livro "As boas mulheres da China", nos revela as condições precárias a que estavam submersas as chinesas moradoras da Colina dos Gritos, onde nunca se vira pobreza que se comparasse com a presenciada pela autora naquela comunidade. Segundo seus relatos "a água era tão preciosa no local que nem mesmo um imperador poderia lavar o rosto e escovar os dentes todos os dias.” (Xinran, 2007, p. 226).

Na colina dos Gritos, os moradores dormiam numa espécie de "casa-caverna”, os alimentos eram preparados sobre um "fogão" improvisado com duas pedras grandes, onde o esterco seco servia de combustível para o fogo e preparo do mingau. Uma vez ao ano as mulheres assavam o pão grosseiro que era guardado nas cavernas, os quais ficavam tão seco que duravam quase um ano e somente os homens que trabalhavam na lavoura tinham o direito de comê-los. As mulheres e as crianças sobreviviam à base do ralo mingau de trigo.

Nesse miserável cenário, (Xinran, 2007, p. 227) relata que "a maior honra e prazer da vida de uma mulher era a tigela de ovos misturados com água que comia depois de ter um filho". Dentro de cada caverna viviam de dez a vinte famílias, onde as mulheres eram usadas como bens de troca, conforme ressalta Xinran:

\begin{abstract}
“As mulheres são valorizadas apenas pela sua utilidade: na qualidade de instrumentos de reprodução, são o artigo de comércio mais precioso na vida dos moradores. Os homens não hesitam em trocar duas ou três filhas pequenas por uma esposa de outra aldeia. A prática mais comum é casar uma mulher da família e arrumar uma esposa em outra aldeia, por isso a maioria das mulheres da colina dos Gritos vem de fora. Depois de se tornarem mães, são forçadas a ceder as filhas. Na colina dos Gritos, a mulher não tem direitos de propriedade nem de herança. Ali também ocorre a prática social incomum de uma esposa ser dividida entre vários maridos. Na maioria desses casos, são irmãos extremamente pobres, sem mulheres para trocar, que compram uma esposa e a compartilham entre si para dar continuidade à família. De dia beneficiam-se da comida e dos trabalhos domésticos que ela faz, e à noite desfrutam do seu corpo. Se tem um filho, nem ela mesma é capaz de dizer quem é o pai. A criança se refere a Papai Grande, Segundo Papai, Terceiro Papai, e assim por diante. Os aldeães não consideram a prática ilegal, porque se trata de um costume estabelecido há muitas gerações, o que o torna mais poderoso do que a lei. Também não zombam das crianças que têm muitos pais, pois elas gozam da proteção e da propriedade de vários homens. Ninguém sente compaixão alguma pelas esposas compartilhadas; para eles, a existência das mulheres é justificada pela sua utilidade." (Xinran, 2007, p. 228-229)
\end{abstract}

A miserabilidade dessas mulheres era tão acentuada que muitas meninas não podiam sair de dentro das cavernas, pois havia uma única roupa e elas tinham que se revezarem no uso da vestimenta para ficarem brincando fora da caverna.

Apesar de todas essas degradações e violações da dignidade da pessoa humana suportadas pelas chinesas, (Xinran, 2007, p. 235) afirma que: "entre as centenas de chinesas com quem eu havia conversado ao longo de quase dez anos de transmissões de rádio e jornalismo, as mulheres da Colina dos Gritos foram as únicas a me dizer que eram felizes.”

Como pode existir felicidade sem dignidade humana e vice-versa? Ponderamos, que não se pode aventar a dignidade humana divorciada da felicidade, pois que configuraria verdadeira aberração jurídica acreditar na existência de um ser humano feliz, tendo sua dignidade humana gravemente violentada.

Em uma análise acurada, é possível afirmar que, o desconhecimento amarrado à perda da dignidade e naturalização dessa condição conduz o ser humano a enxergar por lentes distorcidas a verdadeira essência da felicidade que não pode ser lida segregada da dignidade humana, pois trata-se de um valor moral que ingressa no direito como princípio constitucional, de onde se irradiam todos os demais direitos, nos quais deve ser observado o mínimo existencial, de alimentação, de renda, vestuário, moradia, saúde e previdência.

Afastado desse mínimo existencial integrante da dignidade, as pessoa estariam fadadas à infelicidade, perdendo o interesse por sua existência física, como tem ocorrido no Chile, onde os idosos desprovidos de amparo previdenciário digno e condenados a morrerem trabalhando, tem recorrido ao suicídio (Revista Forum, 2019), desencadeando seu aumento acentuado 
em idosos no país, decorrente da adoção de regime de capitalização previdenciária, que ocasionou reduções de pensões e aposentadorias, tornando-as insuficientes à sobrevivência dos idosos, o que afeta sobremaneira à dignidade e, por conseguinte à felicidade.

Portanto, a dignidade da pessoa humana por ser um valor intrínseco das pessoas, torna-as um fim em si mesmo, o que implica em dizer que ninguém está nesta vida para ser meio para os projetos dos outros, não devendo ser usado para satisfazer objetivo alheio, conforme previsto pelo antiutilitarismo, porquanto, da dignidade humana origina o direito à vida, à igualdade, à integridade física e à integridade moral, elementos essenciais para a garantia da felicidade.

\section{5. “Felicitocracia” e Positivação do Direito à Felicidade na Carta Magna de 1988}

Protagonizando a dianteira da positivação do direito à felicidade, os Estados Unidos da América inseriram na Declaração Americana de 1776, esse direito ao prescrever que:

Artigo $1^{\circ}$ - Todos os homens nascem igualmente livres e independentes, têm direitos certos, essenciais e naturais dos quais não podem, pôr nenhum contrato, privar nem despojar sua posteridade: tais são o direito de gozar a vida e a liberdade com os meios de adquirir e possuir propriedades, de procurar obter a felicidade e a segurança.

Passado mais de um século, vários países como Japão, Nigéria, Coreia do Sul e Butão positivaram a felicidade em suas respectivas constituições. No tocante ao último, aponta Saul Tourinho Leal que:

A Constituição do Butão tratou abertamente da felicidade. O preâmbulo firma o compromisso de "fortalecer a soberania do Butão, para assegurar as bênçãos da liberdade, para assegurar a justiça e a tranquilidade e para reforçar a unidade, felicidade e bem estar das pessoas por todo o tempo." Segundo o artigo $9^{\circ}, 2$, como princípios da política estatal, o estado deve se esforçar para promover as condições que possibilitem encontrar a "Felicidade Nacional Bruta" (Gross National Happiness). O artigo 20, voltado ao Poder Executivo, afirma que o Governo deve proteger e fortalecer a soberania do Reino, proporcionar boa governança, e garantir a paz, segurança, o bem-estar e a felicidade das pessoas. (Leal, 2013, p. 109).

Com efeito, Butão merece destaque, pois "estabeleceu quatro pilares da Felicidade Nacional Bruta, que seriam: (i) boa governança e democratização; (ii) desenvolvimento socioeconômico estável e equitativo; (iii) proteção ambiental; (iv) preservação da cultura." (Leal, 2013, p. 129).

O Brasil, por sua vez, não está alheio às discussões acerca da positivação do direito à felicidade, uma vez que foi sugerido pela Proposta de Emenda Constitucional n 19, também conhecida como "PEC da Felicidade", de autoria do Senador Cristovam Buarque, o acréscimo da felicidade no rol dos direitos sociais, descrito no artigo $6^{\circ}$ da Constituição Federal.

Todavia, a "PEC da Felicidade" foi arquivada, o que nos permite pensar que o Brasil não possui uma visão acurada acerca do relevo creditado à felicidade. Apesar disso, Leal (2013) advoga que o Brasil teria tratado da felicidade no Corpo da Constituição Federal, ressaltando que:

afirmar que a Constituição Federal de 1988 não assegurou o direito à felicidade pelo mero fato de não haver, em seu texto, a palavra felicidade. Primeiramente, há na Constituição, menções, em boa quantidade, à expressão bem-estar, que, para nós, é a maneira neutra que a dogmática constitucional contemporânea optou para travar um prisma da felicidade (...) O que defendemos, portanto, é que a Constituição Federal de 1988 ampara o direito à felicidade explicitamente, quando trata do bem-estar e, implicitamente quando possibilita que ele ingresse no ordenamento jurídico brasileiro aliado a outros dispositivos constitucionais, como o direito à liberdade (direito à bisca da felicidade) ou o direito à saúde (direito prestacional à felicidade). (Leal, 2013, p. 203-204) 
Entendemos que essa abordagem não se confirma, porque há tão-somente menção ao bem-estar, o que por si só não garante direito à felicidade, que necessitaria de positivação explícita no corpo constitucional, obrigando Estado promove-la por meio de prestação positiva como saúde, alimentação, educação, previdência digna, moradia, dentre outros, uma vez que o ser humano necessita de bens exteriores para concretizar felicidade, conforme confissão do próprio Aristóteles, para quem a felicidade é a prática da virtude:

Mas o homem feliz, enquanto homem, necessita também de bens exteriores, pois nossa natureza não basta a si mesma para os fins da contemplação. Nosso corpo também necessita, para ser saudável, de ser alimentado e cuidado. Entretanto, não se deve pensar que o homem, para ser feliz, necessite de muitas ou de grandes coisas, só porque não pode ser sumamente feliz sem bens exteriores. (Aristóteles, 2002, p. 233).

Além dos bens exteriores, para que o Estado promova a felicidade, é fundamental a igualdade de gênero. O exemplo disso é dado por Finlândia, o país mais feliz do mundo, pois de acordo com o Jornal El País (2018) que desde o nascimento da Finlândia como país, há 100 anos, os dois pilares fundamentais da sociedade foram a igualdade e a educação. Foi o primeiro país europeu a conceder o direito de voto às mulheres, em 1906, e em suas últimas eleições três dos oito candidatos dos principais partidos eram mulheres.

A Finlândia é um dos três países com menor disparidade de gênero no mundo, segundo o Fórum Econômico Mundial, além de um longo período de licença-paternidade, que pode se estender por até seis meses, registra El País.

Entretanto, é preciso salientar que, a positivação dessa felicidade poderia guardar uma tremenda arapuca, pois os Estados que a positivaram, sob o revés de fazer seus súditos felizes, desencadearia atitudes tiranas ou terroristas.

Outrossim, a positivação do que seria a felicidade, representaria um terreno fértil para uma possível ditadura da felicidade, onde o Estado invadindo a esfera individual passaria a ditar o que seria ou não felicidade, nos moldes do que ocorre no Reino do Butão, conforme alertado por Saul Tourinho Leal:

Segundo a Constituição, com a finalidade de concretizar um dos pilares da felicidade pelo governo, a cultura do país deve ser preservada a qualquer custo. Nessa linha, uma lei determina que os cidadãos obedeçam ao código de vestimenta nacional e, ao entrarem em prédios públicos, durante o dia, usem roupas expostas no Código. Também há restrições à liberdade acadêmica ou a eventos culturais. A legislação proíbe que pessoas não-butanesas casadas com butanesas promovam qualquer religião diferente do budismo. (...) Uma lei aprovada em 1992 proíbe a crítica ao rei e sistema político. O relacionamento entre pessoas do mesmo sexo é crime. Todavia, a chegada da internet tem ameaçado a postura ortodoxa de preservação da cultura nacional. Jovem tem saído do campo em direção ao divertimento da cidade, contribuindo para a elevação do índice de desemprego na capital, aumentando a quantidade de roubos e tornando crescente o problema de drogas (...) Há, no Butão, o periódico mensal Reporter Butão, dedicado aos nepaleses refugiados. Shanti Ram Acharya, jornalista do periódico, foi condenado a sete anos e meio de prisão, em janeiro de 2009. Ele havia sido preso por supostas atividades subversivas (fotografar um posto do exército). (Leal, 2013, p. 132-133)

Nesse palco, a positivação do que seria felicidade inspira cautela a fim de se evitar a "felicitocracia" e os caprichos de governos fascistas, tendo como pano de fundo a suposta promoção da felicidade, onde, na lição de (Leal, 2013, p. 139) “o uso paternalista e abusivo da teoria da felicidade pelos governos pode desvirtuar todas as premissas sobre as quais se assenta essa teoria."

Desta feita, a "felicitocracia", afastaria sobremaneira a liberdade do indivíduo de escolher a sua felicidade tendo que obedecer a um protótipo de governos de filiação fascista, contrariando as lições sublinhadas por (Cortina, 2009, p. 167) de que "ninguém pode exigir do outro que viva segundo um modelo de felicidade: pode convidá-lo a segui-lo." 
Por derradeiro, entendemos que a ditadura da felicidade poderia acarretar outras misérias humanas desenvolvidas por pessoas de espíritos inferiores, inflamando seus egos e individualismos que, a mercê de obter a felicidade prometida, sepultaria os primados éticos, produzindo efeitos nefastos à vida em sociedade.

\section{Considerações Finais}

Conceituar a felicidade não nos parece ser a tarefa das mais fáceis, ao contrário, é tão árdua quanto à sua incansável busca por tratar-se de um terreno complexo e nebuloso, razão pela qual estaria sendo leviana se apresentasse um conceito universal e válido à todo ser humano.

Todavia, conforme lições de Kant o "ser humano é um fim em si mesmo", é único, não podendo ser valorado ou substituído, pois que, sendo detentor de dignidade não teria preço. Assim, cada um na sua plenitude poderia criar e usufruir do seu "modo de felicidade", respeitando os preceitos éticos para a vida saudável em sociedade.

Deste modo, embora seja desafiador conceituar objetivamente a ser felicidade, notadamente quando envolve variantes em múltiplas searas, que oscilam desde aspecto físicos, econômico, geográfico, cultural, filosófico e espiritual, não se pode cogitar a felicidade dissociada da dignidade humana, pois o antônimo de felicidade, ao contrário do que se pensa, não seria a tristeza, mas sim a ausência de dignidade, sendo aquela mero requisito da condição humana.

Importante salientar, que os desarranjos e empecilhos na conceituação da felicidade, não deve servir de esquivos para a não positivação do direito à felicidade na Constituição Federal, uma vez que esse direito é peça fundamental para completude da dignidade da pessoa humana, nesse tanto, ouçamos o alerta emitido pelo Chile, que possui alarmante índice de suicídio entre idosos, dos quais lhes foram retiradas a dignidade pelo cruel sistema previdenciário adotado que abandona esses idosos à própria sorte.

Contudo, é necessário cautela com a positivação do direito à felicidade para não cair em armadilhas impostas por governos fascistas que a pretexto de positivar esse direito, termine por invadir e inviabilizar a liberdade e plenitude do ser humano com a famigerada "felicitocracia" produzindo efeitos devastadores à vida digna e feliz em sociedade.

De sorte que, entendemos ser imprescindível a positivação do direito à felicidade na Constituição da República Federativa do Brasil de 1988, a fim de que o Estado promova a felicidade do seu povo por meio de prestações positivas como as defendidas no feminismo para os $99 \%$, "lutando por justiça ambiental, educação gratuita de alta qualidade, serviços públicos amplos, habitação de baixo custo, direitos trabalhistas, sistema de saúde gratuito e universal, seja batalhando por um mundo sem racismo nem guerra" (Aruzza; Bhattacharya; Fraser, 2019, p. 34).

Assim, enquanto o Brasil não hospede a felicidade como direito positivado na Constituição Federal, espera-se que garanta aos seres humanos os direitos sociais, como moradia, saúde, educação e alimentação, em especial às pessoas em situação de extrema pobreza e vulnerabilidade a fim de que tenham condições de buscar a felicidade.

\section{Referências}

Aristóteles. (2002) Ética a Nicômaco. Tradução de Pietro Nassetti. Martin Claret.

Aruzza, C., Bhattacharya, T., \& Fraser, N. (2019) Feminismo para os 99\% - Um Manifesto. Tradução de Heci Regina Candiani. São Paulo: Boitempo. Edição Kindle, 2020.

Correio Braziliense. Finlândia é o país mais feliz do mundo, aponta relatório. https://www.correiobraziliense.com.br/app/noticia/mundo/ 2019/03/20/interna_mundo,744209/finlandia-e-o-pais-mais-feliz-do-mundo-mostra-relatorio.shtml

Cortina, Adela. (2009) Ética Mínima. Tradução de Marcos Maciolino. Martins Fontes.

El País. (2018) As razões que fizeram da Finlândia o lugar mais feliz do mundo. https://brasil.elpais.com/brasil/2018/03/14/internacional/1521026096_399451.html 
Research, Society and Development, v. 10, n. 2, e41310212767, 2021

(CC BY 4.0) | ISSN 2525-3409 | DOI: http://dx.doi.org/10.33448/rsd-v10i2.12767

Ferreira, A, B, H. (1986) Novo Dicionário Aurélio da Língua Portuguesa. Editora Nova Fronteira.

Francisco, Luciano Vieira. (2020) Tales de Mileto: Tudo Começa na Água Brasil Escola. https://brasilescola.uol.com.br/filosofia/tales-mileto.htm

Gregório, Sergio Biagi. (2013) Eudamonia. Recuperado em: http://sbgfilosofia.blogspot.com/2013/09/eudaimonia.html.

Kant, Immanuel. (2000) Fundamentos da metafísica do costume. Tradução: Paulo Quintela. Edições 70.

Lakatos, Eva Maria \& Marconi, Marina de Andrade. (2020) Metodologia do Trabalho Científico: projetos de pesquisa / pesquisa bibliográfica / teses de doutorado / dissertação de mestrado / trabalho de conclusão de curso. Atlas, p. 99-217.

LEAL, Saul Tourinho. (2013) Direito à Felicidade: História, Teoria, Positivação e Jurisdição. São Paulo, 2013.365 f. Tese (Doutorado em Direito) Pontifícia Universidade Católica de São Paulo.

Lifestyle. (2020) É feliz? Estes são os países mais felizes em 2020. https://www.noticiasaominuto.com/lifestyle/1440594/e-feliz-estes-sao-os-paises-maisfelizes-em-2020

Revista Forum. (2020) Chile: Capitalização da Previdência faz idosos morrerem trabalhando e suicídio bate recorde. https://revistaforum.com.br/global/chile-capitalizacao-da-previdencia-faz-idosos-morrerem-trabalhando-e-suicidio-bater-recorde/

Xinran. (2007) As boas mulheres da China. Tradução de Manoel Paulo Ferreira. Companhia de Bolso. Edição Kindle, 2020.

Yin, R. K. (2016) Pesquisa qualitativa do início ao fim. Tradução de Daniel Bueno. Penso. 